\title{
両端を弾性支持した剛体棒のジャイロダンパによる振幅低減の数值計算
}

\section{Numerical Analysis of Amplitude Reduction Using Gyroscopic Damper in an Elastically Supported Rigid Rod}

\author{
平井 暦*1 (学生員), 内野 敬介*2 (学生員), 落合 巧樹² (学生員), 杉浦 壽彦*1 (正員)
}

Reki HIRAI (Stu. Mem.), Keisuke UCHINO (Stu. Mem.), Koki OCHIAI (Stu. Mem.), Toshihiko SUGIURA(Mem.)

\begin{abstract}
This paper reports a numerical study about vibration suppression of a rigid rod utilizing gyroscopic effect. Undesirable vibrations occur in vehicles such as automobiles and trains, which can be ideally simplified into an elastically supported rigid rod. The authors aimed to suppress the vibration of a rigid rod supported by superconductive magnetic levitation and suggested a gyroscopic damping as a method. Gyroscopic dampers are often utilized to suppress rotational motions, and rarely used in systems which vibrates in a translational motion. In this study, both ends of the rigid rod are supported by superconducting bulks whose positions are fixed, and the longitudinal axis of the rod is assumed to undergo a planar motion, therefore its motion can be described with 2 DOF. With the rotation of the gyroscopic damper, the system's dynamical behavior can be regarded as $3 \mathrm{DOF}$, hence, in theory, the vibration of the rod can be suppressed. Optimal conditions are derived by fixed point theory, followed by a numerical calculation, and the results were successful.
\end{abstract}

Keywords: gyroscopic damper, the fixed point theory.

\section{1 緒言}

永久磁石と超電導体から構成される磁気浮上系は, 磁気浮上式鉄道，人工衛星の姿勢制御などへの応用が 期待されている $[1,2]$ 。超電導磁気浮上系には，摩擦や 熱伝達による熱歪みが非常に少ないことや, 非制御で の安定した支持が可能であるなどのメリットがある。 一方で，減衰が非常に小さいため，外乱によって振幅 が増大しやすく，並進方向の振動と連成して傾き振動 が生じるといったデメリットも存在する。

振幅の低減方法のひとつに補助質量を用いた動吸 振器がある。主系である構造物に副系となる補助質量 を弾性的に接続することで, 主系の振幅低減を図るも のである。この動吸振器は, 並進振動の振幅低減に用 いられるが，傾き振動の制振には有効ではない。

本研究では，低減衰により生じうる傾き振動に着目 し，ロータを搭載したジャイロダンパによる制振手法 を提案する。ジャイロダンパとは，ロータの回転によ るジャイロ効果を利用した動吸振器であり, 傾き振動 の振幅低減にしばしば用いられている[3]。傾き振動が 生じる超電導磁気浮上系にジャイロダンパを搭載する ことで，並進振動と傾き振動を同時に制振しうる。

連絡先 : 杉浦 壽彦, $\bar{\top} 223-8522$ 神奈川県横浜市港北区 日吉 3-14-6, 慶應義塾大学理工学部機械工学科, e-mail: sugiura@mech.keio.ac.jp

${ }^{* 1}$ 慶應義塾大学 ${ }^{* 2}$ 慶應義塾大学大学院
ここでは，ジャイロダンパによって十分な振幅低減 効果を得られるかどうかを数值計算で確認する。

\section{2 ジャイロダンパを搭載した剛体}

\section{1 解析モデル}

主系の基礎モデルは，両端を弾性支持した剛体棒と して考える。Fig. 1 に具体的なモデル図を示す。この主

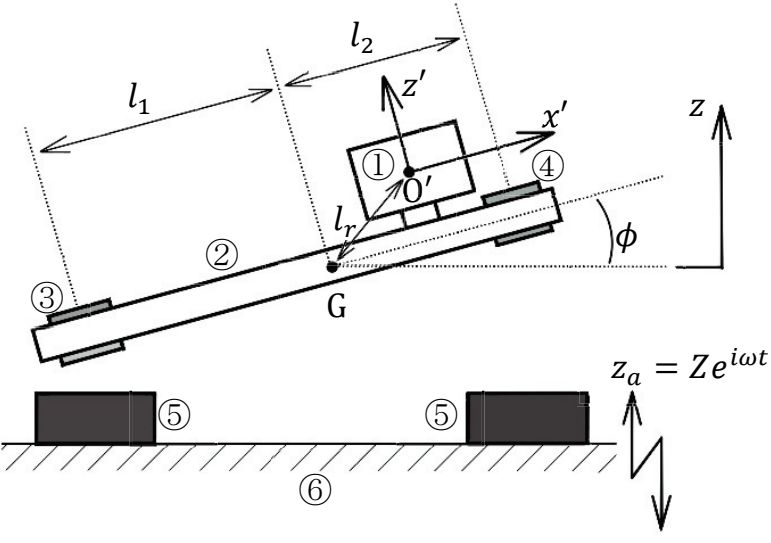

(1) Gyroscopic Damper

(2) Rigid Rod (Target of Vibration Suppression)

(3) Permanent Magnet 1

(4) Permanent Magnet 2

(5) Superconducting Bulk

(6) Vibration Source

Fig. 1 Analytical model of the system. 
系が鉛直方向に並進加振されたとき，鉛直方向の並進 振動と傾き振動が連成した運動となる。副系としてジ ヤイロダンパを搭載することで, 主系の傾き振動とジ ヤイロダンパの傾き振動が連成する。したがって, 主 系の並進振動とジャイロダンパの傾き振動が間接的に 連成することになるため, 主系の並進振動の振幅をジ ヤイロダンパにより低減できる可能性がある。

剛体棒とジャイロダンパを合わせた全体の重心を 点 $\mathrm{G}$ とおき, 点 $\mathrm{G}$ を通り紙面奥手方向に向かう軸を $y$ 軸 とする。点 $\mathrm{G}$ の静的平衡位置からの鉛直方向変位を $z$, 剛体の $y$ 軸周りの変角を $\phi$ と定める。永久磁石 1 , 永久 磁石 2 はそれぞれ $z$ 方向の力 $F_{1}(z), F_{2}(z)$ を受けて浮 上しているものとする。また, 本系では変角 $\phi$ 小さ く, 2 つの永久磁石は $z$ 方向のみに動くとする。Fig. 1 の各パラメータは以下のように定義する。

$l_{1}:$ 点Gから磁石 1 までの長さ

$l_{2}:$ 点Gから磁石 2 までの長さ

$l_{r}:$ 点Gからジャイロダンパの重心までの長さ

次にジャイロダンパ内部の詳細図を Fig. 2 に示寸。 ジャイロロータの中心を原点 $\mathrm{O}^{\prime}$ としでャイロダンパ に固定された座標 $0^{\prime}-x^{\prime} y^{\prime} z^{\prime}$ を定める。 $x^{\prime}$ 軸は剛体棒 の長手方向， $z^{\prime}$ 軸はジャイロロータの回転軸である。

ジャイロロータはジンバルによって $x^{\prime}$ 軸周りにも回 転することができて, その変角を $\theta$ とする。 $x^{\prime}$ 軸には回 転ばねと回転ダンパが付与されており, $\theta$ の回転運動 に対してそれぞれ復元力と減衰力が働く。Fig. 2 の各 パラメータは以下のように定義する。

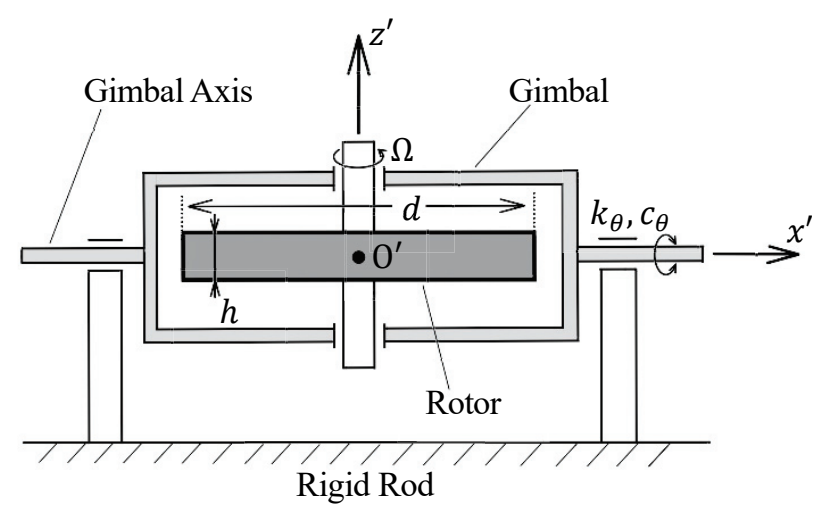

Fig. 2 Analytical model of the gyroscopic damper.
$\Omega$ : ジャイロロータの $z^{\prime}$ 軸周りの回転数

$k_{\theta}: \theta$ に比例する回転ばねのばね定数

$c_{\theta}: \dot{\theta}$ に比例する回転ダンパの減衰係数

$d \quad:$ ジャイロロータの直径

$h$ : ジャイロロータの厚み

\section{2 慣性モーメント}

系全体の $y$ 軸周りの慣性モーメントを $J_{y}$, ジャイロロ 一タの $x^{\prime}$ 軸周りの慣性モーメントをJ $J_{x^{\prime}}$, ジャイロロー タの $z^{\prime}$ 軸周りの慣性モーメントを $J_{z^{\prime}}$ と寸ると, それぞ れ次のように表される。ただし, 剛体棒は長手方向に 一様な棒, ジャイロダンパはジンバル部の質量を無視 できるとみなして導出した。

$$
\begin{gathered}
J_{y}=\frac{1}{3}(M-m)\left(l_{1}^{2}-l_{1} l_{2}+l_{2}^{2}\right)+m\left(\frac{d^{2}}{16}+\frac{h^{2}}{12}+l_{r}^{2}\right) \\
J_{x^{\prime}}=m\left(\frac{d^{2}}{16}+\frac{h^{2}}{12}\right) \\
J_{z^{\prime}}=\frac{1}{8} m d^{2}
\end{gathered}
$$

$M$ は浮上体全体の質量, $m$ はジャイロダンパの質量である。

\section{3 力学的エネルギーの導出}

系の運動エネルギーは並進の運動エネルギー $T_{t}$ とジ ヤイロ効果を考慮した回転の運動エネルギー $T_{r}$ に分け られる[4]。それぞれ次のようになる。

$$
T_{t}=\frac{1}{2} M \dot{z}^{2}
$$

$$
T_{r}=\frac{1}{2} J_{y} \dot{\phi}^{2}+\frac{1}{2} J_{x^{\prime}} \dot{\theta}^{2}+\frac{1}{2} J_{z^{\prime}}\left(\Omega^{2}-2 \Omega \phi \dot{\theta}\right)
$$

そして, 静的平衡位置を基準としたポテンシャルエネ ルギーUは

$$
\begin{gathered}
U=\int_{0}^{z-l_{1} \phi-z_{a}} F_{1}(u) d u+\int_{0}^{z+l_{2} \phi-z_{a}} F_{2}(u) d u \\
+\frac{1}{2} k_{\theta} \theta^{2}
\end{gathered}
$$

のように表される。

これらを用いてラグランジアンLを表すと

$$
L=T_{t}+T_{r}-U
$$


となる。なお減衰による散逸関数 $D$ は次のよう。

$$
D=\frac{1}{2} c_{\theta} \dot{\theta}^{2}
$$

\section{3 運動方程式}

\section{1 運動方程式の導出}

ラグランジアン $L$ 散逸関数 $D$ を用いて $, z, \phi, \theta$ に ついてのラグランジュの運動方程式をそれぞれ表すと

$$
\begin{aligned}
& \frac{d}{d t}\left(\frac{\partial L}{\partial \dot{z}}\right)-\frac{\partial L}{\partial z}+\frac{\partial D}{\partial \dot{z}}=0 \\
& \frac{d}{d t}\left(\frac{\partial L}{\partial \dot{\phi}}\right)-\frac{\partial L}{\partial \phi}+\frac{\partial D}{\partial \dot{\phi}}=0 \\
& \frac{d}{d t}\left(\frac{\partial L}{\partial \dot{\theta}}\right)-\frac{\partial L}{\partial \theta}+\frac{\partial D}{\partial \dot{\theta}}=0
\end{aligned}
$$

となり，これらの式に式(7)と式(8)を代入することで

$$
\begin{aligned}
& M \ddot{z}-F_{1}\left(z-l_{1} \phi-z_{a}\right) \\
&-F_{2}\left(z+l_{2} \phi-z_{a}\right)=0 \\
& J_{y} \ddot{\phi}+l_{1} F_{1}\left(z-l_{1} \phi-z_{a}\right) \\
&-l_{2} F_{2}\left(z+l_{2} \phi-z_{a}\right)+J_{z^{\prime}} \Omega \dot{\theta}=0 \\
& J_{x^{\prime}} \ddot{\theta}+c_{\theta} \dot{\theta}+k_{\theta} \theta-J_{z^{\prime}} \Omega \dot{\phi}=0
\end{aligned}
$$

と求まる。式(12)と式(13)では，それぞれ力，モーメン 卜の次元でZと $\phi か ゙$ 連成している。また, 式(13)と式(14) では, ジャイロ効果によって $J_{z^{\prime}} \Omega$ に比例した項ができ, それによって連成している。

\section{$3.2 F_{1}$ と $F_{2}$ の近似}

永久磁石が受ける $z$ 方向の力 $F(z)$ は超電導体が永久 磁石に及ぼす浮上力 $F_{S C}(z)$ と浮上体の重量 $F_{g}$ を用いて

$$
F(z)=F_{S C}(z)-F_{g}
$$

と表せる。発展鏡像法を用いて $F_{S C}$ を求めると

$$
F_{S C}(z)=\frac{3 M^{2}}{2 \pi \mu_{0}}\left[\frac{1}{16\left(z+z_{s t}\right)^{4}}-\frac{1}{\left(z+z_{s t}+z_{0}\right)^{4}}\right]
$$

となる[5]。ただし，Mは磁気モーメント， $\mu_{0}$ は真空の 透磁率, $z_{s t}$ は永久磁石の静的平衡位置と超電導体の距 離, $z_{0}$ は永久磁石の初期位置と超電導体の距離である。

$F(z)$ を $z=0$ 近傍で Taylor 展開すると

$$
F(z)=-k z+k^{\prime} z^{2}-k^{\prime \prime} z^{3}+\cdots
$$

となる。 $k, k^{\prime}, k^{\prime \prime}$ は正の定数である。本系では振幅が
小さく，非線形項が無視できる場合について考えるた め, 以下からは一次の項の夕を用いて

$$
F_{1}(z)=-k_{1} z, \quad F_{2}(z)=-k_{2} z
$$

と表すこととする。だだし $, k_{1}, k_{2}$ は浮上力の線形項の 剛性である。

\section{3 運動方程式の無次元化}

式(12), 式(13)に式(18)と加振項 $z_{a}=Z e^{j \omega t}$ を代入す るとそれぞれ

$$
\begin{aligned}
M \ddot{z}+\left(k_{1}+k_{2}\right) z+\left(k_{2} l_{2}-\right. & \left.k_{1} l_{1}\right) \phi \\
& =\left(k_{1}+k_{2}\right) Z e^{j \omega t} \\
\left(k_{2} l_{2}-k_{1} l_{1}\right) z+J_{y} \ddot{\phi}+\left(k_{1} l_{1}^{2}+k_{2} l_{2}^{2}\right) \phi+J_{z^{\prime}} \Omega \dot{\theta} & \\
& =\left(k_{2} l_{2}-k_{1} l_{1}\right) Z e^{j \omega t}
\end{aligned}
$$

のように変形される。式(19), 式(20), 式(14)を無次元 化すると, 次のようになる。ただし, 変数を無次元化 したものを(*)をつけて表すこととする。

$$
\begin{gathered}
\ddot{z}^{*}+z^{*}+\phi^{*}=e^{j v t^{*}} \\
\alpha \ddot{\phi}^{*}+\beta \phi^{*}+z^{*}+\gamma \dot{\theta}^{*}=e^{j v t^{*}} \\
\ddot{\theta}^{*}+\zeta \dot{\theta}^{*}+\kappa \theta^{*}-\gamma \dot{\phi}^{*}=0
\end{gathered}
$$

各無次元パラメータは以下のように定義した。vは無 次元加振周波数, $\alpha$ は無次元慣性モーメント, $\beta$ は無次 元剛性，〈は無次元ダンパ内減衰係数， $\kappa$ は無次元ダン パ内剛性である。

$$
\begin{aligned}
Z & =Z z^{*}, \phi=\frac{k_{1}+k_{2}}{k_{2} l_{2}-k_{1} l_{1}} Z \phi^{*} \\
\theta & =Z \sqrt{\frac{M}{J_{x^{\prime}}}} \theta^{*}, \quad t=\frac{t^{*}}{\omega_{n}} \\
\omega_{n} & =\sqrt{\frac{k_{1}+k_{2}}{M}}, \quad v=\frac{\omega}{\omega_{n}} \\
\alpha & =\frac{J_{y}}{M}\left(\frac{k_{1}+k_{2}}{k_{2} l_{2}-k_{1} l_{1}}\right)^{2} \\
\beta & =\frac{\left(k_{1}+k_{2}\right)\left(k_{1} l_{1}^{2}+k_{2} l_{2}^{2}\right)}{\left(k_{2} l_{2}-k_{1} l_{1}\right)^{2}} \\
\gamma & =\frac{J_{z^{\prime}} \Omega}{k_{2} l_{2}-k_{1} l_{1}} \sqrt{\frac{k_{1}+k_{2}}{J_{x^{\prime}}}} \\
\zeta & =\frac{c_{\theta}}{J_{x^{\prime}} \omega_{n}}, \quad \kappa=\frac{k_{\theta}}{J_{x^{\prime}} \omega_{n}^{2}}
\end{aligned}
$$




\section{4 定点理論を用いた最適設計条件の導出}

定点理論によれば，動吸振器における主系の制振効 果を最大にするパラメータが得られる。通常, 定点理 論は一自由度の主系に対して活用される理論である。

しかし，本系は主系が二自由度系であるため，条件式 が非常に煩雑になってしまい，解を導出することが困 難である。そこで, 条件式の一部に適当な近似を施し, 特殊な条件下の二自由度系に対する定点理論を適用で きるようにして最適設計解を導出する $[6] 。$

主系の振幅の周波数応答曲線において，無次元減衰 係数ろが変化しても必ず通る定点が 4 つ存在する。そ の中で無次元加振周波数 $v$ のさい方から 2 点を点P, 点Qと定める。この 2 点での振幅の大きさが等しくな る条件を最適同調条件，極大值となるような条件を最 適減衰条件とする。主系の鉛直方向変位 $\boldsymbol{Z}$ に着目し，こ の 2 つの条件を同時に満たすような最適設計值を導出 する。

\section{1 応答振幅}

式(21)～式(23)の定常解は $z^{*} ， \phi^{*} ， \theta^{*}$ をそれぞれ

$$
z^{*}=A e^{j v t}, \quad \phi^{*}=B e^{j v t}, \quad \theta^{*}=C e^{j v t}
$$

とおいて式(21)〜式(23)に代入することにより求まる。 特に, $Z^{*}$ の応答振幅 $|A|, \phi^{*}$ の応答振幅 $|B|$ は

$$
|A|=\sqrt{\frac{R_{1}^{2}+R_{2}^{2}}{R_{5}^{2}+R_{6}^{2}}}, \quad|B|=\sqrt{\frac{R_{3}^{2}+R_{4}^{2}}{R_{5}^{2}+R_{6}^{2}}}
$$

となる。ここで，式(25)中の各項は次のようになる。

$$
\begin{aligned}
R_{1}= & -\alpha v^{4}+\left(\beta+\gamma^{2}+\alpha \kappa-1\right) v^{2}-\kappa(\beta-1) \\
R_{2}= & \zeta v\left\{\alpha v^{2}-(\beta-1)\right\} \\
R_{3}= & -v^{4}+\kappa v^{2} \\
R_{4}= & \zeta v^{3} \\
R_{5}= & \alpha v^{6}-\left(\alpha+\beta+\gamma^{2}+\alpha \kappa\right) v^{4} \\
& \quad+\left(\beta+\gamma^{2}+\alpha \kappa+\beta \kappa-1\right) v^{2}-\kappa(\beta-1) \\
R_{6}= & \zeta v\left\{-\alpha v^{4}+(\alpha+\beta) v^{2}-(\beta-1)\right\}
\end{aligned}
$$

\section{2 最適同調条件}

点 $\mathrm{P}$, 点 $\mathrm{Q}$ における無次元加振周波数 $v$ をれぞれ $v_{p}, v_{q}\left(0<v_{p}<v_{q}\right)$ とおく。それらを求めるために, 無 次元減衰係数

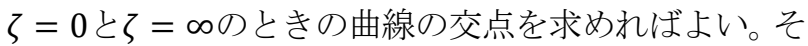
れぞれのろを代入した $|A|$ は

$$
|A|_{\zeta=0}=\left|\frac{R_{1}}{R_{3}}\right|, \quad|A|_{\zeta=\infty}=\left|\frac{R_{2}}{R_{4}}\right|
$$

であり，これらの交点の方程式は

$$
|A|_{\zeta=0}=|A|_{\zeta=\infty}
$$

となるが，非常に煩雑で解の導出が困難である。そこ で, $|A|_{\zeta=\infty}$ を近似することにより，解の導出を可能に する。 $|A|_{\zeta=\infty}$ の共振点における無次元加振周波数を $v_{1}, v_{2}\left(0<v_{1}<v_{2}\right)$ とすると

$$
\left\{\begin{array}{l}
v_{1}^{2}=\frac{(\alpha+\beta)-\sqrt{(\alpha-\beta)^{2}+4 \alpha}}{2 \alpha} \\
v_{2}^{2}=\frac{(\alpha+\beta)+\sqrt{(\alpha-\beta)^{2}+4 \alpha}}{2 \alpha}
\end{array}\right.
$$

であり，これを用いて $|A|_{\zeta=\infty}$ を表すと

$$
|A|_{\zeta=\infty}=\left|\frac{S}{v_{1}^{2}-v^{2}}\right|
$$

のように変形できる。ただし，Sは次のよう。

$$
S=\frac{\alpha v^{2}-(\beta-1)}{\alpha\left(v^{2}-v_{2}^{2}\right)}
$$

$S を v=1$ 近傍でテイラー展開すると，定数項に比べて 1次以上の項が非常に小さいため, $v=1$ を代入して

$$
T=\frac{\alpha-(\beta-1)}{\alpha\left(1-v_{2}^{2}\right)}
$$

のような定数として扱うこととする。以上より，近似 した応答振幅 $|A|_{\zeta=\infty}^{\prime}$ は次のようになる。

$$
|A|_{\zeta=\infty}^{\prime}=\left|\frac{T}{v_{1}^{2}-v^{2}}\right|
$$

式(27)の $|A|_{\zeta=\infty}$ を $|A|_{\zeta=\infty}^{\prime}$ に置き換え, $|A|_{\zeta=0}$ と $|A|_{\zeta=\infty}^{\prime}$ の位相は交点において逆位相となることを考慮 すると，方程式は

$$
\frac{R_{1}}{R_{3}}=-\frac{T}{v_{1}^{2}-v^{2}}
$$

となる。なお以下からは，式(33)から求まる 3 点のう ち 2 点を点 $\mathrm{P}$, 点 $\mathrm{Q}$ となす。式(33)を用いて特殊な条 件下の二自由度系に対する定点理論を考えることで， 
最適同調条件は

$$
2 v_{1}^{2}\left(V_{1}-2 v_{1}^{2}\right)^{2}-V_{2}\left(V_{1}-2 v_{1}^{2}\right)+V_{3}=0
$$

と求まり，このときの $v_{p}, v_{q}$ は

$$
\left\{\begin{array}{l}
v_{p}^{2}=v_{1}^{2}-\sqrt{v_{1}^{4}-\frac{V_{3}}{V_{1}-2 v_{1}^{2}}} \\
v_{q}^{2}=v_{1}^{2}+\sqrt{v_{1}^{4}-\frac{V_{3}}{V_{1}-2 v_{1}^{2}}}
\end{array}\right.
$$

とわかる。そして式(33)を満たす無次元ばね定数 適同調值 $\kappa_{\mathrm{opt}}$ となる。ただし，各係数は次のようにな る。

$$
\begin{gathered}
V_{1}=\frac{T\left(\alpha+\beta+\gamma^{2}+\alpha \kappa\right)+\alpha v_{1}^{2}+\beta+\gamma^{2}+\alpha \kappa-1}{(1+T) \alpha} \\
\begin{array}{r}
V_{2}=\left\{T\left(\beta+\gamma^{2}+\alpha \kappa+\beta \kappa-1\right)\right. \\
+v_{1}^{2}\left(\beta+\gamma^{2}+\alpha \kappa-1\right) \\
+\kappa(\beta-1)\} /\{(1+T) \alpha\}
\end{array} \\
V_{3}=\frac{\kappa(\beta-1)\left(T+v_{1}^{2}\right)}{(1+T) \alpha}
\end{gathered}
$$

\section{3 最適減衰条件}

点 $\mathrm{P}$, 点Qにおける無次元振幅 $|A|$ が極大となるため には

$$
\frac{\partial}{\partial v^{2}}|A|_{v=v_{p}}^{2}=0, \quad \frac{\partial}{\partial v^{2}}|A|_{v=v_{q}}^{2}=0
$$

を満たすような弓の值を求めればよい。それぞれ求め たろに $\kappa=\kappa_{\mathrm{opt}}$ を代入して得られる各值を $\zeta_{p}, \zeta_{q}$ とおい て，無次元最適減衰值を次のように定義する。

$$
\zeta_{\mathrm{opt}}=\frac{\zeta_{p}+\zeta_{q}}{2}
$$

\section{5 数値計算結果}

超電導体側が加振された場合の主系の振動振幅の 周波数応答を数值計算により求める。Table 1 に今後予 定する実験に対応するパラメータの值を示す。このと き， $\alpha=1.82, \beta=5.00$ となる。また，同じく実験で 予定するジャイロロータの回転数 $\Omega$ として, 4,000 rpm,
8,000 rpm と 12,000 rpm の各場合に対応する無次元パ ラメータ $\gamma$, 無次元最適設計值 $\kappa_{\mathrm{opt}}, \zeta_{\mathrm{opt}}$, 最適設計值 $k_{\theta-\mathrm{opt}}, c_{\theta-\mathrm{opt}}$ を Table 2 に示す。以下では, Table 1 お よび Table 2 のパラメータのときの応答について扱う。

無回転の場合も含めて，各回転数での主系の鉛直振 動振幅の周波数応答 (無次元) を Fig. 3 に示す。なお, 図中の曲線は全て式(25)に基づく理論曲線である。

この図によれば，ロータが無回転のときは，ジャイ ロ効果がないため，主系はダンパの変角 $\theta$ とは連成せ ず, $z$ と $\phi$ みの減衰のない 2 自由度系として 2 つの共 振点を有する応答を示す。一方，ロータ回転時は，ジ ヤイロ効果によりダンパ内の自由度も含めた 3 自由度 系の応答を示し，3 つの共振点が現れる。その共振周 波数は，低い側から順に，無回転時の低次の共振周波 数よりやや低い側とやや高い側，さらに無回転時の高 次の共振周波数よりやや高い側にずれた值となる。口 一タ回転数 $\Omega$ が大きいほど，この各共振周波数のずれ は大きくなるとともに，各点での共振振幅は小さくな る。

回転数 $\Omega$ が 4,000 rpm と $12,000 \mathrm{rpm}$ の曲線を比較す ると, 加振角周波数 $v$ が 1 付近の振幅が約 $46 \%$ 抑えら れている。これは回転数 $\Omega$ と共にジャイロ効果も大き くなり，振動抑制効果が高まるためと考えられる。

次に, Fig. 4 に, Fig. 3 の=12,000 rpm の理論曲線（実 線) と, 式(12)〜式(13)に対する 4 次の数值積分結果 (赤 丸）を示す。両者の一致から，理論式の妥当性が確認

Table 1 Parameter values given in this study.

\begin{tabular}{|c||c||c||c|}
\hline$d(\mathrm{~m})$ & $h(\mathrm{~m})$ & $M(\mathrm{~kg})$ & $m(\mathrm{~kg})$ \\
\hline 0.0530 & 0.0120 & 0.400 & 0.100 \\
\hline$l_{1}(\mathrm{~m})$ & $l_{2}(\mathrm{~m})$ & $l_{r}(\mathrm{~m})$ & \\
\hline 0.300 & 0.100 & 0.0500 & \\
\hline$k_{1}(\mathrm{~N} / \mathrm{m})$ & $k_{2}(\mathrm{~N} / \mathrm{m})$ & $\Omega(\mathrm{rpm})$ & \\
\hline 1,000 & 1,000 & 12,000 & \\
\hline
\end{tabular}

Table 2 Parameter values of the gyroscopic damper optimized by the fixed point theory.

\begin{tabular}{|c||c|c|c|c|}
\hline$\Omega(\mathrm{rpm})$ & 0 & 4,000 & 8,000 & 12,000 \\
\hline \hline$\gamma(-)$ & 0 & -0.759 & -1.52 & -2.28 \\
\hline$\kappa_{\text {opt }}(-)$ & - & 0.834 & 1.16 & 1.71 \\
\hline$\zeta_{\text {opt }}(-)$ & - & 0.262 & 0.642 & 1.21 \\
\hline$k_{\theta-\text { opt }}(\mathrm{N})$ & - & 0.0782 & 0.109 & 0.161 \\
\hline$c_{\theta-\text { opt }}\left(10^{-4} \mathrm{~N} \cdot \mathrm{s}\right)$ & - & 3.48 & 8.52 & 16.0 \\
\hline
\end{tabular}


できる。

Fig. 3 の鈶直振動振幅に対する主系の傾き $\phi$ の無次元 振幅 $|B|$ の理論曲線を Fig. 5 に示寸。Fig. 3 と同様, 口 一夕回転数 $\Omega$ が大きいほど $\phi$ 共振ピークも小さくな っており, 回転数 $\Omega$ が $4,000 \mathrm{rpm}$ と $12,000 \mathrm{rpm}$ の曲線を 比較すると, 加振角周波数 $v$ が 1 付近の振幅が約 $38 \%$ 抑えられている。

以上のことから，ジャイロダンパのロータ回転数を

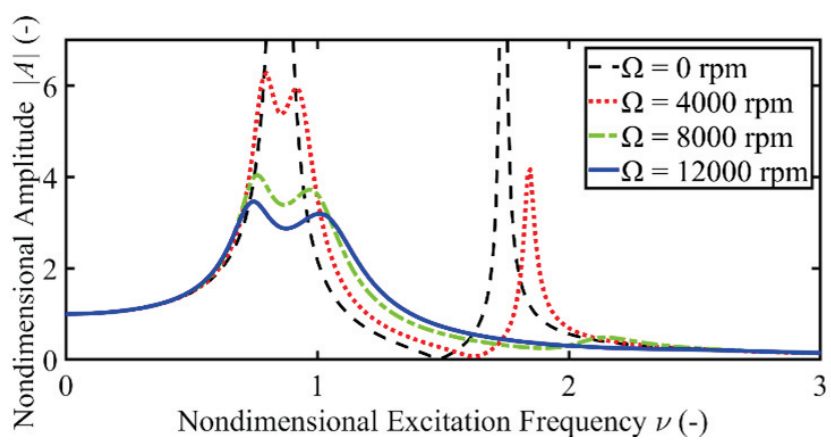

Fig. 3 Nondimensional frequency response curves of the rigid rod. (translational motion)

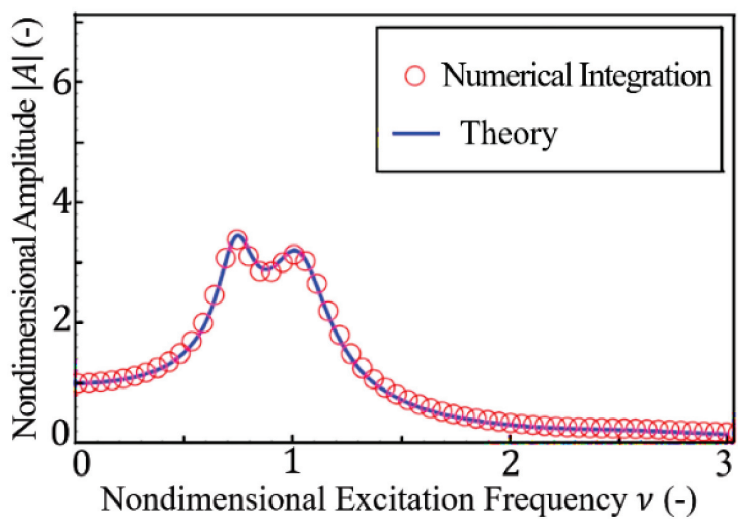

Fig. 4 Comparison of theorical curve and plots obtained by numerical integration. (translational motion of the rigid rod, $\Omega=12,000 \mathrm{rpm}$ )

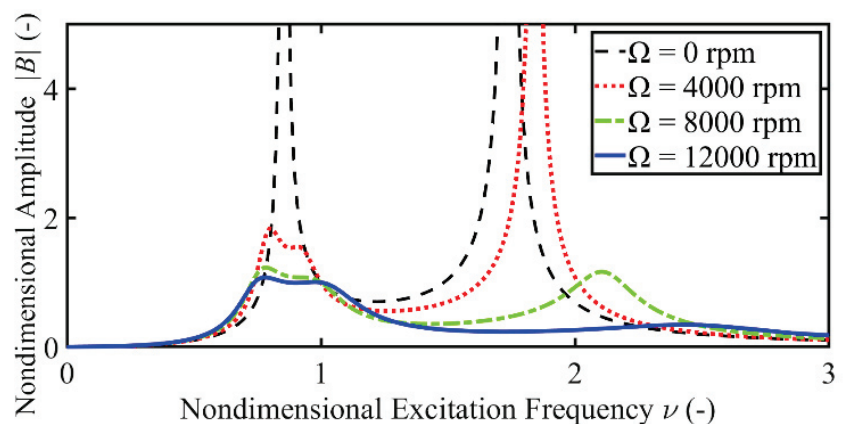

Fig. 5 Nondimensional frequency response curves of the rigid rod. (rotational motion)
3 倍にすることで，主系の並進振動の共振ピークは約 $46 \%$ 抑制，傾き振動の共振ピークは約 $38 \%$ 抑制とな り，並進・傾き振動を同時に振幅低減できることを数 值的に確認した。無次元化に基づいて定点理論より導 出したこの最適設計值によれば，この例とは異なるパ ラメータ設定の主系に対しても並進・傾き振動を同時 に振幅低減できると考えられる。

\section{6 結論}

鈆直方向と 1 方向の傾きに自由度を持つ基礎的な 2 自由度モデルの超電導磁気浮上系にジャイロダンパを 付与した系を考え，定点理論を用いて制振の近似的な 最適解を導出し，並進と傾きの同時制振効果を数值計 算で確認した。今後，実験を行い，この結果を検証す る。また，浮上系は，実際にはより多くの自由度を持 つため，多自由度系の制振手法も検討予定である。

\section{参考文献}

[1] 藤本，高温超電導バルク磁石の磁気浮上式鉄道への応用 可能性, 低温工学, 34 巻, 11 号, pp. 549-555.

[2] T. Shibata and S. Sakai, Passive Micro Vibration Isolator Utilizing Flux Pinning Effect for Satellites. Journal of Physics: Conference Series, Vol. 744, No. 1, IOP Publishing, 2016, doi:10.1088/1742-6596/744/1/012009.

[3] 西原, 松久, 佐藤, ジャイロモーメントを用いる制振機 構，日本機械学会論文集 $\mathrm{C}$ 編，57 巻，534 号，1991.

[4] 岡本, 小谷, 林, 薮野, 須田, ジャイロを用いた鉄道車両 に生じる蛇行動現象の安定化, 日本機械学会論文集 C 編, 74 巻, 738 号, pp. 235-241， 2008.

[5] T. Sugiura and Y. Uematsu, Analysis of Electromagnetic Force and Torque in High-Tc Superconducting Levitation Based on the Advanced Mirror Image Method，日本機械学会論文集 C 編, Vol. 66, No. 644, pp. 1138-1145, 2000.

[6] 富室, 田村, 定点理論による二自由度系を対象と した動吸振器の設計, 日本機械学会論文集 C 編, 78 巻, 786 号, pp. 372-381, 2012. 